\title{
Perioperative Prophylactic Antibiotics in Orthopaedic
}

\section{Surgery.}

\author{
Bikram Prasad Shrestha ${ }^{1}$, Surya Raj Niraula², Parvin Nepal', Guru Prasad Khanal ${ }^{1}$, Navin Karn ${ }^{1}$, \\ Pashupati Chaudhary', Raju Rijal', Rajiv Maharjan'.
}

\section{${ }^{1}$ Department of Orthopaedics, B.P.Koirala Institute of Health Sciences, Dharan, Nepal; ${ }^{2}$ School of Public Health and Community Medicine, B.P.Koirala Institute of Health Sciences, Dharan, Nepal}

\begin{abstract}
Introduction: In our country, various institutes have different protocols for postoperative antibiotics. Many western literature have mentioned that administration of prophylactic antibiotics for longer than 24 hours has no advantage and may actually lead to superinfection with drug-resistant organisms. Because of environmental and theater condition most of the surgeon here are very reluctant to use prophylactic antibiotics for only 24 hours. The objective of the study was to find out the effect of duration of prophylactic antibiotics on the rate of surgical site infection in clean elective orthopaedic surgeries.
\end{abstract}

Methods: This was a randomized controlled trial involving 207 clean elective orthopaedic patients undergoing surgery. The patients were divided into three groups which received intravenous prophylactic antibiotics for 24 hours, 48 hours and 48 hours followed by 7 days of oral antibiotics respectively. The patients were followed up for three months postoperatively.

Result: There was no significant difference in the rate of surgical site infection among the three groups.

Conclusion: We conclude that there is no benefit in prolonging prophylactic antibiotics beyond 24 hours.

Keywords: antibiotics; prophylactic antibiotics; surgical site infection.

\section{INTRODUCTION}

Surgical site infection is one of the most dreaded complications faced by an orthopaedic surgeon ${ }^{1}$. There are multiple studies which support prophylactic antibiotic administration for 24 hours postoperatively rather than multiple days ${ }^{2-4}$. We conducted a survey which showed that most of the surgeons use antibiotics (Intravenous and Oral) for two weeks. There is indeed a resistance to minimize the duration of Intravenous (IV) antibiotics to 24 hours among Nepalese surgeons in spite of its advocacy in the orthopaedic literature.

The concern to limit the use of perioperative antibiotics to 24 hours is not just for economic reasons (Rs 15,00,000 extra per 10,000 patients if cheapest antibiotic is used for 48 hours in stead of 24 hours postoperatively). Continuing antibiotics for longer than 24 hours after wound closure may contribute to the development of antimicrobial resistance ${ }^{5-7}$. Administration of prophylactic antibiotics for longer than 24 hours has not been demonstrated to be effective and may actually lead to superinfection with drug-resistant organisms ${ }^{5-13}$.
Most of the operation theatre conditions in Nepal are not as ideal as in more affluent countries from where most of the literature abound. Most of us feel more assured against infection by administering antibiotics for a longer period.

It had become absolutely necessary to validate in our conditions what the surgeons in the developed countries have been advocating. This study was performed to see if there was any difference in the rate of infection among patients who received 24 hours of IV antibiotics and those who received the same for longer duration, in our setting.

\section{Correspondance}

\section{Dr Bikram Prasad Shrestha}

Department of Orthopaedics, B.P. Koirala Institute of Health Sciences, Dharan, Nepal.

Email: bkrmstha@gmail.com 


\section{METHODS}

This was a randomized controlled trial conducted in the Department of Orthopaedics, B.P. Koirala Institute of Health Sciences, Dharan, Nepal. The study population included a total of 240 clean elective cases operated by the authors with or without using implants from $1^{\text {st }}$ March 2009 to $8^{\text {th }}$ November 2009 . The 240 patients were randomized into 3 groups using the random number generated by the software available at http:/www. randomization.com.

Patients belonging to Group A were administered two gm of inj. cephazolin and $80 \mathrm{mg}$ inj. gentamicin within 60 minutes before incision. Postoperatively, inj. Caphazolin one gm and inj. Gentamicin $80 \mathrm{mg}$ was repeated eight hourly for 24 hours. It was not followed with oral antibiotics. When the duration of surgery exceeded two hours or when there was excessive bleeding, one dose of each antibiotic was repeated intraoperatively.

Patients belonging to Group B were administered the same antibiotics as in Group A but postoperatively, it was continued for 48 hours. No oral antibiotics were administered after 48 hours.

Group $\mathrm{C}$ patients were administered antibiotics as in Group B but was followed with oral cephadroxyl 500mg twice daily for 7 days. In all cases doses were adjusted in pediatric patients.

The study was approved by the Ethical Review Board of the Research Committee of B.P.Koirala Institute of Health Sciences. Informed consent was taken from all patients.

The pro formas for each patient included information about age, gender, duration of surgery(incision to closure), associated medical illness, preoperative haemoglobin level, preoperative albumin level, blood loss during surgery and preoperative admission days. The patients were discharged 48 hours after the surgery after wound inspection and change of dressing. The patients were followed up at 14 days, six weeks and at three months to look for signs of surgical site infection.

Our criteria for judging whether or not a wound infection occurred were as follows which has been modified from that of Alan et al. ${ }^{14}$

1. If a wound drained purulent material irrespective of whether an organism was cultured or not it was considered infected.

2. When a wound became red, painful or tender, swollen and hot for more than 48 hours, the wound was considered infected.

3. When the patient had fever for more than 48 hours and no other cause could be traced, the wound was considered infected.
4. If the patient had a stitch abscess with a small amount of purulence directly around a suture, but without any signs of inflammation or fever, the wound was not considered infected.

Data were entered into Microsoft Office Excel program and analyzed using SPSS (Statistical Package for Social Sciences) version 17.0 software. Preliminary analysis was performed by calculating percentage, mean and standard deviation to get an idea about the proportion, central tendency and dispersion respectively. Chi-square and Mann-Whitney tests were applied to find the association of surgical site infection with duration of antibiotic administration after adjusting the rest of explanatory variables. A p value $<0.05$ was considered significant.

\section{RESULTS}

Of the 240 patients we included in the study, 33 were lost to follow up. So the pro formas of 207 patients were analyzed. There were 75 patients in Group A, 67 in group B and 65 in group C. Out of the 207 patients, 146 were males and 61 were females.

The proportion of infection among males is nearly twice as those in females. However, there is no statistical association between infection and gender $(p>0.05)$ (Table1 and figure 1).

\section{Table 1. Relation of infection to gender}

\begin{tabular}{|l|l|l|l|l|}
\hline \multirow{2}{*}{ Gender } & \multicolumn{2}{|c|}{ Infection } & \multirow{2}{*}{ Total } & \multirow{2}{*}{ P value } \\
\cline { 2 - 4 } & Absent & Present & & \\
\hline Male & $137(93.8 \%)$ & $9(6.2 \%)$ & 146 & \multirow{2}{*}{0.399} \\
\hline Female & $59(96.7 \%$ & $2(3.3 \%)$ & 61 & \\
\hline
\end{tabular}

Figure 1. Sex distribution among participants in three groups

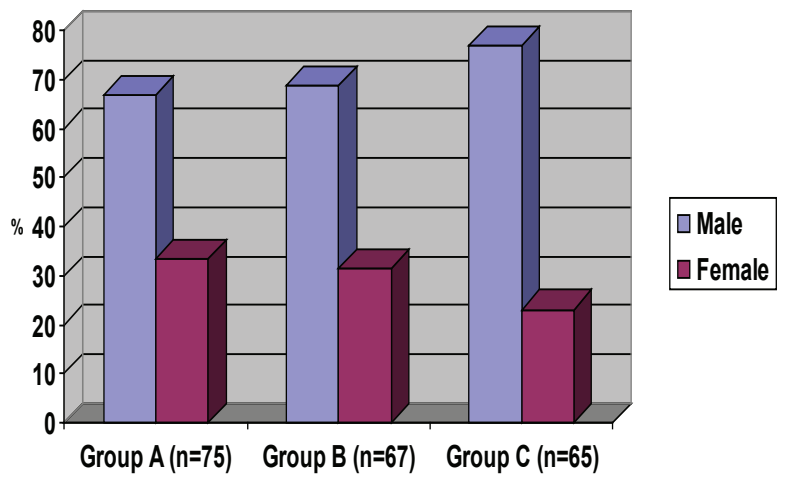

The variables such as age, duration of surgery, preoperative haemoglobin, blood loss during surgery, preoperative 
Table 2. Measures of different variables in three different groups

\begin{tabular}{|l|l|l|l|l|}
\hline Variables & Group A $(\mathrm{n}=75)$ & Group B $(\mathrm{n}=67)$ & Group C (n=65) & P value* \\
\hline Age & $39.36 \pm 21.59$ & $34.30 \pm 21.55$ & $34.52 \pm 19.18$ & 0.270 \\
\hline Duration of surgery (min) & $83.07 \pm 48.45$ & $83.66 \pm 52.09$ & $85.38 \pm 46.38$ & 0.822 \\
\hline $\begin{array}{l}\text { Preoperative Haemoglobin }(\mathrm{gm} / \\
\text { dl) }\end{array}$ & $12.42 \pm 2.08$ & $12.360 \pm 2.00$ & $13.812 \pm 8.56$ & 0.501 \\
\hline Blood loss (ml) & $177.27 \pm 166.61$ & $154.40 \pm 140.01$ & $232.92 \pm 217.21$ & 0.060 \\
\hline Preoperative albumin (gm/dl) & $4.324 \pm 0.71$ & $4.467 \pm 1.0327$ & $4.31 \pm 0.769$ & 0.796 \\
\hline Preoperative admission days & $4.53 \pm 4.37$ & $3.10 \pm 3.631$ & $3.18 \pm 3.14$ & 0.063 \\
\hline
\end{tabular}

* Probabilities based on Kruskal Wallis test

albumin level and preoperative admission days were compared among the three groups and was found to be statistically insignificant showing that randomization was successful (Table 2).

The means of above variables were also compared among those who had infection and those who did not. All the variables were found to have no association with infection except the duration of surgery (Table 3 ). The mean duration of surgery among those who did not have infection was 82.70 minutes whereas it was 106.82 minutes in those with infection $(\mathrm{p}<0.05)$. The most common medical illness that we encountered was hypertension followed by diabetes mellitus. The association of presence of associated illness in the three groups were not significant (Table 4).The proportion of infection present among those with or without medical illness was almost homogenous $(\mathrm{p}>0.05)$ (Table 5).

The percentages of infection in all groups were uniformly high. Four $(5.3 \%)$ out of 75 were infected in Group A. Similarly there were three out of $67(4.5 \%)$ in Group B and 4 out of 61(6.2\%) infection in Group C. The mean percentage of infection was $5.3 \%$ (Table 6).

The most important question that this study sought to answer was: 'Does administering antibiotics for prolonged periods decrease the chance of surgical site infection?' Logistic regression test, after adjusting other variables performed to examine the relationship of infection to the three groups answered that there was no difference of significance in the rate of infection between any groups $(\mathrm{p}>0.05)$.
Postoperative infections have been shown to significantly increase morbidity, extend the patient's hospital stay, drastically increase the cost of the medical system and cause severe physical limitations that diminish the quality of life $\mathrm{e}^{15}$. Decreasing the incidence of surgical site infection is a matter of utmost interest to both the patients and surgeons.

Literature is flooded with articles that relate surgical site infection to a variety of factors of which some are modifiable, some are not. The use of prophylactic antibiotics is one of the most important factors in decreasing infection and one that all surgeons are concerned about.

The clinical use of prophylactic antibiotics in orthopaedic surgery was not always supported. Early poorly designed studies found that perioperative use of antibiotics in clean orthopaedic cases was associated with increased infection rates ${ }^{16,17}$. Despite these unfavourable results, investigations continued into the use of prophylactic antibiotics in orthopaedic surgery ${ }^{6}$.

All orthopaedic surgeons in Nepal believe in using prophylactic antibiotics but there is discrepancy in the duration of their use. Available literature recommends the use of prophylactic antibiotics for 24 hours only and advise against using them for longer periods. It was necessary to find out whether longer use of antibiotics decreased the incidence of infection in our setting which is less than ideal.

Factors like duration of surgery, associated medical illness, preoperative haemoglobin status, preoperative serum albumin level, amount of blood loss during surgery and preoperative admission days would be expected to influence the incidence of infection. Malnutrition is a known risk factor for deep infection after a variety of 
Table 3. Relation of age, duration of surgery, preoperative haemoglobin level, blood loss during surgery, preoperative albumin level and preoperative admission days to infection.

\begin{tabular}{|l|l|l|l|l|l|l|}
\hline Infection & Age & $\begin{array}{l}\text { DoS } \\
\text { (in min) }\end{array}$ & $\begin{array}{l}\text { Preop. Hb level } \\
\text { (in gm/dl) }\end{array}$ & $\begin{array}{l}\text { B l 0 0 d } \\
\text { loss } \\
\text { (in ml) }\end{array}$ & $\begin{array}{l}\text { Preop. Alb. } \\
\text { level } \\
\text { (in gm/dl) }\end{array}$ & $\begin{array}{l}\text { P r e 0 p } \\
\text { a d m is s i o n } \\
\text { days }\end{array}$ \\
\hline $\begin{array}{l}\text { Infection Present } \\
\text { Mean }\end{array}$ & $\begin{array}{l}33.64 \\
\text { Std. Deviation }\end{array}$ & $\begin{array}{l}106.82 \\
15.468\end{array}$ & $\begin{array}{l}13.091 \\
1.9481\end{array}$ & $\begin{array}{l}204.55 \\
178.12\end{array}$ & $\begin{array}{l}4.582 \\
0.4535\end{array}$ & $\begin{array}{l}3.55 \\
2.911\end{array}$ \\
\hline $\begin{array}{l}\text { Infection Absent } \\
\text { Mean }\end{array}$ & 36.35 & 82.70 & 12.824 & 186.38 & 4.353 & 3.65 \\
Std. Deviation & 21.173 & 48.794 & 5.2258 & 179.20 & 0.8592 & 3.871 \\
\hline $\begin{array}{l}\text { Total } \\
\text { Mean }\end{array}$ & 36.20 & 83.99 & 12.838 & 187.34 & 4.365 & 3.65 \\
Std. Deviation & 20.888 & 48.803 & 5.1028 & 178.76 & 0.8431 & 3.821 \\
\hline P value & 0.868 & 0.042 & 0.344 & 0.628 & 0.274 & 0.797 \\
\hline
\end{tabular}

DOS- Duration of surgery, Preop Hb-Preoperative Haemoglobin, Preop. Alb- Preoperative Albumin

Table 4. Associated medical illness (ASM) with infection according to the three groups

\begin{tabular}{|c|c|c|c|c|c|c|}
\hline INFECTION & $\begin{array}{l}\text { ASSOCIATED } \\
\text { MEDICAL ILLNESS }\end{array}$ & \multicolumn{3}{|c|}{ GROUP } & Total & \multirow[t]{2}{*}{ P Value } \\
\hline & & A & B & C & & \\
\hline \multirow[b]{3}{*}{ PRESENCE } & PRESENCE & $1(25.0 \%)$ & $1(33.3 \%)$ & $0(0.0 \%)$ & $2(18.2 \%)$ & \multirow[b]{3}{*}{$N A^{*}$} \\
\hline & ABSENCE & $3(75.0 \%)$ & $2(66.7 \%)$ & $4(100.0 \%)$ & $9(81.8 \%)$ & \\
\hline & Total & $4(36.36 \%)$ & $3(27.27 \%)$ & $4(36.36 \%)$ & $11(100.00 \%)$ & \\
\hline \multirow[b]{3}{*}{ ABSENCE } & PRESENCE & $16(22.5 \%)$ & $9(14.1 \%)$ & $8(13.1 \%)$ & $33(16.8 \%)$ & \multirow[b]{3}{*}{0.271} \\
\hline & ABSENCE & $55(77.5 \%)$ & $55(85.9 \%)$ & $53(86.9 \%)$ & $163(83.2 \%)$ & \\
\hline & Total & $\begin{array}{c}71 \\
(36.22 \%)\end{array}$ & $\begin{array}{c}64 \\
(32.65 \%)\end{array}$ & $\begin{array}{c}61 \\
(31.12 \%)\end{array}$ & $\begin{array}{c}196 \\
(100.00 \%)\end{array}$ & \\
\hline
\end{tabular}

orthopaedic surgical procedures ${ }^{18,19}$. A serum albumin level of less than $3.5 \mathrm{~g} / \mathrm{dl}$ has been associated with an increase in wound complications ${ }^{20}$. In our study $11 \%$ of the patients had serum albumin less than $3.5 \mathrm{~g} / \mathrm{dl}$. We found only the duration of surgery had a statistical association with the incidence of infection. Longer the duration of surgery, more was the chance of surgical site infection. Perhaps our sample size was not large enough.

The mean infection rate in our study was $5.3 \%$ which must be considered high. We do not know the infection rate of other institutions in Nepal. The infection rate in a study by Pavel et al. ${ }^{13}$ in which the patients received cephaloridine was $2.85 \%$ and the study by Henley et al. ${ }^{21}$ in which the patients received cefamandole was $1.6 \%$. Postoperative infection has been estimated to occur following $1 \%$ to $2 \%$ of all total hip arthroplasties and $2 \%$ to $4 \%$ of all total knee arthroplasties in the United States ${ }^{22,23}$. In our study there was no statistical difference between the rate of infection among those who received 24 hours of antibiotics and those who received the same for longer durations. This shows the futility of administering antibiotics for longer 
${ }^{*} \chi^{t}$ test is not applicable

Table 5 The relation of associated medical illness to infection

\begin{tabular}{|c|c|c|c|c|c|}
\hline \multirow{2}{*}{\multicolumn{2}{|c|}{ ASSOCIATED MEDICAL ILLNESS }} & \multicolumn{2}{|c|}{ INFECTION } & \multirow{2}{*}{ TOTAL } & \multirow{2}{*}{ P value } \\
\hline & & PRESENT & ABSENT & & \\
\hline AMI & Count & 9 & 163 & 172 & \multirow{6}{*}{0.908} \\
\hline Absent & $\%$ within the infected group & $5.2 \%$ & $94.8 \%$ & $83.1 \%$ & \\
\hline AMI & Count & 2 & 33 & 35 & \\
\hline Present & $\%$ within the infected group & $5.7 \%$ & $94.3 \%$ & $16.9 \%$ & \\
\hline \multirow{2}{*}{ Total } & Count & 11 & 196 & 207 & \\
\hline & $\%$ within the infected group & $100.0 \%$ & $100.0 \%$ & $100.7 \%$ & \\
\hline
\end{tabular}

AMI: associated medical illness

Table 6. The percentages of infection among the three groups

\begin{tabular}{|c|c|c|c|c|c|}
\hline \multirow{2}{*}{\multicolumn{2}{|c|}{ GROUP }} & \multicolumn{2}{|c|}{ INFECTION } & \multirow{2}{*}{ TOTAL } & \multirow{2}{*}{ P value } \\
\hline & & ABSENT & PRESENT & & \\
\hline GROUP A & $\begin{array}{l}\text { Count } \\
\% \text { within group }\end{array}$ & $\begin{array}{l}71 \\
94.7 \%\end{array}$ & $\begin{array}{l}4 \\
5.3 \%\end{array}$ & $\begin{array}{l}75 \\
100 \%\end{array}$ & \\
\hline GROUP B & $\begin{array}{l}\text { Count } \\
\% \text { within group }\end{array}$ & $\begin{array}{l}64 \\
95.5 \%\end{array}$ & $\begin{array}{l}3 \\
4.5 \%\end{array}$ & $\begin{array}{l}67 \\
100 \%\end{array}$ & \\
\hline GROUP C & $\begin{array}{l}\text { Count } \\
\% \text { within group }\end{array}$ & $\begin{array}{l}61 \\
93.8 \%\end{array}$ & $\begin{array}{l}4 \\
6.2 \%\end{array}$ & $\begin{array}{l}65 \\
100 \%\end{array}$ & 0.912 \\
\hline TOTAL & $\begin{array}{l}\text { Count } \\
\text { percentage }\end{array}$ & $\begin{array}{l}196 \\
94.7\end{array}$ & $\begin{array}{l}11 \\
5.3\end{array}$ & $\begin{array}{l}207 \\
100 \%\end{array}$ & \\
\hline
\end{tabular}

than 24 hours.

\section{CONCLUSION}

We conclude that in clean elective orthopaedic surgeries, administering prophylactic antibiotics for more than 24 hours postoperatively provide no additional advantage.

\section{ACKNOWLEDGEMENT}

The authors are thankful to all patients who participated in the study and to the Research Committee of B.P.Koirala Institute of Health Sciences, Dharan.

\section{REFERENCE:}

1. Nicholas F, D'Mitri S, Marschall BB, William TO. Prevention of perioperative infection. J Bone Joint Surg Am 2007; 89:1605-18.

2. Koulenti D, Rello J. Hospital-acquired pneumonia in the 21st century: a review of existing treatment options and their impact on patient care. Expert Opin Pharmacother. 2006; 7:1555-69.

3. Rello J, Sa-Borges M, Correa H, Leal SR, Baraibar J. Variations in etiology of ventilator-associated pneumonia 
across four treatment sites: implications for antimicrobial prescribing practices. Am J Respir Crit Care Med. 1999;160:608-13.

4. Trouillet JL, Chastre J, Vuagnat A, Joly-Guillou ML, Combaux D, Dombret MC, Gibert C. Ventilator-associated pneumonia caused by potentially drug-resistant bacteria. Am J Respir Crit Care Med. 1998; 157:531-9.

5. Li JT, Markus PJ, Osmon DR, Estes L, Gosselin VA, Hanssen AD. Reduction of vancomycin use in orthopedic patients with a history of antibiotic allergy. Mayo Clin Proc 2000;75:902-6.

6. Oishi CS, Carrion WV, Hoaglund FT. Use of parenteral prophylactic antibiotics in clean orthopedic surgery. A review of the literature. Clin Orthop Relat Res 1993; 296:249-55.

7. Bratzler DW, Houck PM, Surgical Infection Prevention Guidelines Writers Workgroup,: Antimicrobial prophylaxis for surgery: An advisory statement from the National Surgical Infection Prevention Project. Clin Infect Dis 2004; 38:1706-1715.

8. Slobogean GP, Kennedy SA, Davidson D, O'Brien PJ. Single-versus multiple-dose antibiotic prophylaxis in the surgical treatment of closed fractures: a meta-analysis. $J$ Orthop Trauma. 2008;22:264-9.

9. Prokuski L.Prophylactic antibiotics in Orthopaedic surgery. J Am Acad orthop Surg 2008 May;16(5):283-293.

10. Slobogean GP, Kennedy SA, Davidson D, O'Brien PJ. Single-versus multiple-dose antibiotic prophylaxis in the surgical treatment of closed fractures: a meta-analysis. $J$ Orthop Trauma. 2008; 22:264-9.

11. Heydemann JS, Nelson CL. Short-term preventive antibiotics. Clin Orthop Relat Res 1986 Apr;(205):184-7.

12. Nelson CL, Green TG, Porter RA, Warren RD. One day versus seven days of preventive antibiotic therapy in orthopedic surgery. Clin Orthop Relat Res. 1983; 176:258-63.
13. Williams DN, Gustilo RB. The use of preventive antibiotics in orthopaedic surgery. Clin Orthop Relat Res. 1984; 190:83-8.

14. Pavel A, Smith RL, Ballard A, Larsen IJ. Prophylactic antibiotics in clean orthopaedic surgery. J Bone Joint Surg Am. 1974; 56:777-82.

15. Whitehouse JD, Friedman ND, Kirkland KB, Richardson WJ,Sexton DJ.The impact of surgical-site infections following orthopaedic surgery at a community hospital and a university hospital: adverse quality, excess length of stay, and extra cost. Infect Control Hosp Epidemiolo.2002; 23:183-9.

16. Tachdjian MO, Compere EL: Postoperative wound infections in orthopedic surgery: Evaluation of prophylactic antibiotics. J Int Coll Surg 1957; 28:797-805.

17. Olix ML, Klug TJ, Coleman CR, Smith WS: Prophylactic antibiotics in elective operations on bones, joints, and tendons. Surg Forum 1960; 10:818-819.

18. Dreblow DM, Anderson CF, Moxness K. Nutritional assessment of orthopedic patients. Mayo Clin Proc. 1981; 56:514.

19. Greene KA, Wilde AH, Stulberg BN. Preoperative nutritional status of total joint patients. Relationship to postoperative wound complications. J Arthroplasty. 1991; 6:321-5.

20. Fairfield KM, Fletcher RH. Vitamins for chronic disease prevention in adults: scientific review. JAMA. 2002;287:3116-26. Erratum in: JAMA. 2002; 288:1720.

21. Henley MB, Jones RE, Wyatt RWB, Hofmann A, Cohen RL: Prophylaxis with cefamandole nafate in elective orthopedic surgery. Clin Orthop Relat Res 1986; 209:249-254.

22. An YH, Friedman RJ. Prevention of sepsis in total joint arthroplasty. J Hosp Infect.1996;33-93-108.

23. Berbari EF, Hanssen AD, Duffy MC, Steckleberg JM, Ilstrup DM, Harmsen WS, Osmon DR. Risk factors for prosthetic joint infection: case control study. Clin Infect Dis. 1998; 27:1247-54. 